\title{
The role of $\mathrm{Ni}$ in increasing the reversibility of the hydrogen release from nanoconfined $\mathrm{LiBH}_{4} \dagger$
}

\author{
Peter Ngene, ${ }^{a}$ Margriet H. W. Verkuijlen, ${ }^{c}$ Qiang Zheng, ${ }^{a b}$ \\ Joris Kragten, ${ }^{a}$ P. Jan M. van Bentum, ${ }^{c}$ Johannes H. Bitter ${ }^{a}$ \\ and Petra E. de Jongh $* a$
}

\author{
Received 17th December 2010, Accepted 17th January 2011 \\ DOI: $10.1039 / c 0 f d 00028 k$
}

\begin{abstract}
Nanoconfinement and the use of catalysts are promising strategies to enhance the reversibility of hydrogen storage in light metal hydrides. We combined nanoconfinement of $\mathrm{LiBH}_{4}$ in nanoporous carbon with the addition of $\mathrm{Ni}$. Samples were prepared by deposition of 5-6 nm Ni nanoparticles inside the porous carbon, followed by melt infiltration with $\mathrm{LiBH}_{4}$. The $\mathrm{Ni}$ addition has only a slight influence on the $\mathrm{LiBH}_{4}$ hydrogen desorption, but significantly enhances the subsequent uptake of hydrogen under mild conditions. Reversible, but limited, intercalation of $\mathrm{Li}$ is observed during hydrogen cycling. X-ray diffraction shows that the initial crystalline 5-6 nm Ni nanoparticles are not present anymore after melt infiltration with $\mathrm{LiBH}_{4}$. However, transmission electron microscopy showed Ni-containing nanoparticles in the samples.

Extended X-ray absorption fine structure spectroscopy proved the presence of $\mathrm{Ni}_{x} \mathrm{~B}$ phases with the $\mathrm{Ni}-\mathrm{B}$ coordination numbers changing reversibly with dehydrogenation and rehydrogenation of the sample. $\mathrm{Ni}_{x} \mathrm{~B}$ can act as a hydrogenation catalyst, but solid-state ${ }^{11} \mathrm{~B}$ NMR proved that the addition of $\mathrm{Ni}$ also enhanced the reversibility of the system by influencing the microstructure of the nanoconfined $\mathrm{LiBH}_{4}$ upon cycling.
\end{abstract}

\section{Introduction}

The use of hydrogen as an energy carrier for automobile applications has attracted much attention. It is most useful if the hydrogen is produced using renewable energy sources such as wind or solar electricity. If used in conjunction with a fuel cell to drive a car, only water is emitted from the exhaust. However, an important technical bottleneck is the development of a compact and effective onboard hydrogen storage system. Hydrogen can be stored as a gas under high pressure (typically 800 bar). Alternatively, reversible hydrogen storage in porous solids or metal hydrides is considered, offering advantages in terms of safety and volumetric hydrogen content. ${ }^{1,2}$ One of the materials that is extensively being investigated is lithium borohydride $\left(\mathrm{LiBH}_{4}\right)$ which has a gravimetric and volumetric hydrogen content of $18.5 \mathrm{wt}^{\%} \%$ and $121 \mathrm{~kg} \mathrm{H}_{2} \mathrm{~m}^{-3}$ respectively, making it attractive for hydrogen storage

${ }^{a}$ Inorganic Chemistry and Catalysis, Debye Institute for Nanomaterials Science, Utrecht University, Sorbonnelaan 16, 3584 CA Utrecht, The Netherlands. E-mail: P.E.deJongh@uu.nl; Fax: +3130251 1027; Tel: +31302536766

${ }^{b}$ Delft Chem Tech, Delft University of Technology, Julianalaan 136, 2600 GA Delft, The Netherlands

'Institute for Molecules and Materials, Radboud University, Heyendaalseweg 135, 6525 AJ Nijmegen, The Netherlands

$\dagger$ Electronic supplementary information (ESI) available. See DOI: 10.1039/c0fd00028k 
for cars. However due to the high stability of the compound, high temperatates reve Online required to release the hydrogen. In addition, the hydrogen release is only partially reversible, and only under harsh conditions such as $600{ }^{\circ} \mathrm{C}$ and 350 bar hydrogen pressure. ${ }^{3,4}$ This at present renders $\mathrm{LiBH}_{4}$ unfit for reversible hydrogen storage in fuel cell cars.

It is worthwhile to study strategies to improve the hydrogen sorption kinetics and reversibility in complex metal hydrides. Nanosizing/nanoconfinement in porous materials such as carbon, ${ }^{5-10}$ and the use of catalysts, ${ }^{11-17}$ are among the strategies being explored to improve the dehydrogenation and rehydrogenation behaviour. These approaches have been shown to be effective for several hydrides such as $\mathrm{NH}_{3} \mathrm{BH}_{3}{ }^{18}$ and $\mathrm{NaAlH}_{4} \cdot{ }^{19}$ Recently, it has been demonstrated that not only the kinetics, but also the thermodynamical stability of complex metal hydrides can be affected. ${ }^{20,21}$ In the case of $\mathrm{LiBH}_{4}$, Gross et al. ${ }^{5}$ demonstrated that the desorption temperature of $\mathrm{LiBH}_{4}$ was lowered by $75{ }^{\circ} \mathrm{C}$ and the dehydrogenation rates at $300{ }^{\circ} \mathrm{C}$ increased up to 50 times when incorporated into a carbon scaffold. Furthermore, the nanoconfined $\mathrm{LiBH}_{4}$ shows a reversible hydrogen uptake $(75 \%$ of original capacity) at relatively mild conditions of 100 bar $\mathrm{H}_{2}, 400{ }^{\circ} \mathrm{C}$ for $2 \mathrm{~h}$.

Bogdanovič and Schwickardi first showed that Ti-based compounds are effective catalysts for the dehydrogenation and rehydrogenation reactions of $\mathrm{NaAlH}_{4}{ }^{22}$ Although the exact role of $\mathrm{Ti}$ is still not well understood, the discovery led to a new interest in finding catalysts that could also be effective for other complex hydrides such as $\mathrm{LiBH}_{4}$. The search for an efficient catalyst for hydrogenation and dehydrogenation reactions of $\mathrm{LiBH}_{4}$ was pioneered by Züttel et al. who first reported that $\mathrm{SiO}_{2}$ acted as a catalyst for the dehydrogenation of $\mathrm{LiBH}_{4} \cdot{ }^{11}$ However later research showed that $\mathrm{SiO}_{2}$ reacts with $\mathrm{LiBH}_{4}$ to form stable silicates ${ }^{23,24}$ while irreversibly releasing hydrogen, as is the case with most metal oxide additives. ${ }^{25,26} \mathrm{~A}$ large range of materials, including metal halides, ${ }^{12,14,27} \mathrm{Al}$, Pt, carbon nanotubes, fullerene and $\mathrm{Ni}^{13,15-17,28}$ has been investigated in an effort to identify an effective catalyst for $\mathrm{LiBH}_{4}$ de/rehydrogenation. Addition of these materials generally led to a decrease in the dehydrogenation temperatures but most of the systems still required temperatures above $400{ }^{\circ} \mathrm{C}$ and hydrogen pressures above 40 bar for only achieving partial rehydrogenation of the desorbed material. For example $600{ }^{\circ} \mathrm{C}, 100$ bar $\mathrm{H}_{2}$ and $30 \mathrm{~h}$ were required for partial $\left(12 \mathrm{wt} \% \mathrm{H}_{2}\right)$ reversibility in $\mathrm{LiBH}_{4}$ ball milled with $\mathrm{Ni}^{16}\left(600^{\circ} \mathrm{C}\right.$ and 350 bar hydrogen for bulk $\left.\mathrm{LiBH}_{4}\right)$.

We previously reported the synergetic effect of nanoconfinement and addition of $\mathrm{Ni}$ on the reversibility of the hydrogen release from $\mathrm{LiBH}_{4} \cdot{ }^{29}$ In this paper we discuss how $\mathrm{Ni}$ nanoparticles increase the reversibility of the hydrogen desorption. Although $\mathrm{Ni}$ is a classical hydrogenation catalyst, for complex metal hydrides usually the dissociation of hydrogen molecules at the surface is not the rate limiting factor. Rather solid state diffusion, microstructure, and nucleation of phase transformations seem to play a role. We hence discuss the structural changes and phase evolution of the nanoconfined $\mathrm{LiBH}_{4}$ during cycling in the presence and absence of $\mathrm{Ni}$.

\section{Experimental details}

Carbon-supported Ni nanoparticles were prepared by incipient wetness impregnation. ${ }^{30}$ Nickel nitrate (99\%, Acros) and citric acid (99.5\%, Acros) were mixed in a $3: 2$ molar ratio in demineralized water resulting in a bright green nickel citrate solution. Typically, $0.66 \mathrm{ml}$ of the solution was added to $1 \mathrm{~g}$ high surface area graphite (HSAG 500) under static vacuum. HSAG 500 is high purity $(99.9 \%)$ graphitic carbon from Timcal Switzerland. It contains mesopores (mostly 2-3 nm) up to $20 \mathrm{~nm}$ in diameter, has $500 \mathrm{~m}^{2} \mathrm{~g}^{-1}$ BET surface area and a total pore volume of $0.66 \mathrm{~cm}^{3} \mathrm{~g}^{-1}$. The impregnated sample was dried in air overnight at $120{ }^{\circ} \mathrm{C}$, calcined by heating to $450{ }^{\circ} \mathrm{C}$ under $\mathrm{N}_{2}$ flow and reduced in a flow of a gas mixture of $5 \% \mathrm{H}_{2}$ in $\mathrm{N}_{2}$ with $1 \mathrm{~h}$ dwell at $400{ }^{\circ} \mathrm{C}$. 
$25 \mathrm{wt}^{\%} \mathrm{LiBH}_{4}$ (Acros-organics $95 \%$ pure) was incorporated into the Niredmpregle Online nated carbon by melt infiltration. The required amounts of $\mathrm{Ni} / \mathrm{C}$ nanocomposites and $\mathrm{LiBH}_{4}$ were placed in a graphite sample holder and inserted into a stainless steel autoclave. An initial pressure of $50 \mathrm{bar} \mathrm{H}_{2}$ was applied and the sample was heated at $3{ }^{\circ} \mathrm{C} \mathrm{min}-1$ to $295^{\circ} \mathrm{C}$ and allowed to stay for $30 \mathrm{~min}$ at $295^{\circ} \mathrm{C}$ at a final pressure of $\approx$ 100 bar $\mathrm{H}_{2}$. The sample was then allowed to cool down to room temperature, the pressure was released and the samples were stored in a glove box. Apart from $\mathrm{Ni}$ impregnation, all other sample handling was under Ar atmosphere in a glove-box (contamination typically less than $1 \mathrm{ppm}$ of $\mathrm{O}_{2}$ and $\mathrm{H}_{2} \mathrm{O}$ ) to avoid exposure and contamination. Nanocomposites containing $25 \mathrm{wt} \% \mathrm{LiBH}_{4}$ and different $\mathrm{Ni}$ loadings on carbon $(0 \mathrm{wt} \%, 5 \mathrm{wt} \%$, and $10 \mathrm{wt} \%)$ were synthesized and labeled according to the weight percentage of these materials in the composites. For example the sample $25 \mathrm{LiBH}_{4} / 3.75 \mathrm{Ni} / \mathrm{C}$ contains $25 \mathrm{wt} \% \mathrm{LiBH}_{4}, 3.75 \mathrm{wt} \% \mathrm{Ni}$ and $71.25 \mathrm{wt} \% \mathrm{C}$.

Sample characterization was performed using X-Ray Diffraction (XRD), $\mathrm{N}_{2}$-physisorption, Transmission Electron Microscopy (TEM), Extended X-ray Absorption Fine Structure spectroscopy (EXAFS) and solid-state Nuclear Magnetic Resonance (NMR) measurements. All measurements (except TEM) were done in air tight sample holders. XRD patterns were obtained at room temperature from 18 to $80^{\circ} 2 \theta$ with a Bruker-AXS D-8 Advance X-ray diffractometer setup using $\operatorname{CoK} \alpha_{1,2}$ radiation with $\lambda=1.790 \AA$. The Ni crystallite sizes were derived from analysis of the width of the $52.2^{\circ} 2 \theta$ diffraction peak using the Debye-Scherrer method and assuming a Scherrer constant of 0.94 and corrected for experimental line broadening. $\mathrm{N}_{2}$-physisorption measurements were performed at $-196{ }^{\circ} \mathrm{C}$, using a Micromeritics Tristar 3000 apparatus. The pore size distributions of the samples were calculated from the desorption branch using BJH theory with the Harkins and Jura thickness equation. Transmission Electron Micrographs (TEM) were obtained using a Tecnai $20 \mathrm{~F}$ microscope operating at $200 \mathrm{kV}$ acceleration voltage, equipped with a $\mathrm{LaB}_{6}$ electron source and a TWIN objective lens. Particle size histograms were determined from dark-field images analyzing 100-200 crystallites. The electron diffraction pattern was determined using a camera constant of 720 .

Nickel K-edge $(8333 \mathrm{eV})$ EXAFS spectra of the as-prepared, dehydrogenated and rehydrogenated $\mathrm{Ni}$-containing nanocomposites $\left(25 \mathrm{LiBH}_{4} / 3.75 \mathrm{Ni} / \mathrm{C}\right)$ were recorded at beamline $\mathrm{C}$ of the DORIS III storage ring at the Deutsches Elektronen-Synchrotron (DESY), Hamburg. The beamline is equipped with a Si (111) double-crystal monochromator, which is detuned to $60 \%$ of the Bragg peak intensity to suppress higher harmonics. About $50 \mathrm{mg}$ sample was pressed into a pellet, mounted to the cell, and transferred to the beamline without air exposure. The samples were measured in transmission mode at room temperature in Ar flow. A $7 \mu$ m thick $\mathrm{Ni}$ foil $(99.99 \%)$ and $\mathrm{Ni}_{2} \mathrm{~B}$ powder $(99.5 \%$, Acros) were measured at liquid nitrogen temperature as reference materials. Data reduction was performed with XDAP ${ }^{31}$ in order to obtain the Fourier transformed (FT) EXAFS, phase-uncorrected Fourier transformed $\chi(k)$ EXAFS and the FEFF fits from the measured spectra. At least three scans from a sample were averaged. The edge-energy was determined from the maximum of the first derivative of the spectrum using the $\mathrm{Ni}$ foil as a standard reference. The background signal before the edge jump was fitted with a smooth spline, and substracted. ${ }^{32}$ The obtained data were normalized by setting the signal height $(50 \mathrm{eV})$ after the edge to 1 . Experimental data are fitted in $\mathrm{R}$-space with $k^{2}$ weighting using the difference file techniques in real space ${ }^{33}$ and the quality of the fit checked by applying $k^{1}$ and $k^{3}$ weightings.

Solid-state NMR experiments were performed on a $600 \mathrm{MHz}$ Varian spectrometer using a $2.5 \mathrm{~mm} \mathrm{HX}$ MAS probe. ${ }^{11} \mathrm{~B}$ single pulse excitation spectra were obtained using a short hard pulse of $0.20 \mu$ s at effective rf-field strength of $140 \mathrm{kHz}$ after taking pulse rise and decay times into account. A sample spinning speed of $15 \mathrm{kHz}$ was applied. The ${ }^{11} \mathrm{~B}$ spectra were referenced with respect to an aqueous solution of $\mathrm{H}_{3} \mathrm{BO}_{3}(\delta=19.6 \mathrm{ppm})$ and shifts are given relative to $\mathrm{BF}_{3} \cdot \mathrm{OEt}_{2}(\delta=0 \mathrm{ppm})$. 
Hydrogen release properties of the nanocomposites were measured bytempetiale Online ture programmed desorption (TPD) using a Micromeritics AutoChem II 2920 apparatus. 100 to $150 \mathrm{mg}$ of sample was heated at $5{ }^{\circ} \mathrm{C} \mathrm{min}-1$ from room temperature to 400 or $450{ }^{\circ} \mathrm{C}$ in $25 \mathrm{ml} \mathrm{min}{ }^{-1}$ Ar flow with a dwell time of $25 \mathrm{~min}$ at the maximum temperature. The composition of the desorbed gas was analyzed using a quadrupole mass spectrometer (MS) with purified Ar as carrier gas. Rehydrogenation of the desorbed samples was performed in an autoclave by heating at $2{ }^{\circ} \mathrm{C} \mathrm{min}^{-1}$ with initial pressure of 20 bar $\mathrm{H}_{2}$ to $320^{\circ} \mathrm{C}$ and dwelling at $320^{\circ} \mathrm{C}$ for 120 min at a final pressure of 40 bar.

\section{Results and discussion}

\section{Hydrogen sorption}

Fig. 1 shows the hydrogen release from samples heated to $400{ }^{\circ} \mathrm{C}$ and dwelled at this temperature for $25 \mathrm{~min}$. As a reference the desorption pattern from $25 \mathrm{wt} \% \mathrm{LiBH}_{4}$ melted with non porous graphite (BET surface area $7 \mathrm{~m}^{2} \mathrm{~g}^{-1}$ ) is included. Hydrogen release started in the $\mathrm{LiBH}_{4} /$ graphite sample around $280{ }^{\circ} \mathrm{C}$ with two minor hydrogen release peaks around $280{ }^{\circ} \mathrm{C}$ and $350{ }^{\circ} \mathrm{C}$. The majority of the hydrogen is desorbed only at higher temperatures as reported in the literature. ${ }^{5}$ For the $\mathrm{LiBH}_{4} / \mathrm{C}$ nanocomposite, hydrogen desorption started around $200{ }^{\circ} \mathrm{C}$, with a maximum release rate at $350{ }^{\circ} \mathrm{C}$. The onset temperature of hydrogen release is slightly lower (below $200{ }^{\circ} \mathrm{C}$ ) in the $\mathrm{Ni}$ containing nanocomposites. Increasing the $\mathrm{Ni}$ concentration from 3.75 to $7.5 \mathrm{wt} \%$ did not have a significant effect on the hydrogen release. Quantitative analysis of the hydrogen desorption shows that all the nanocomposites had released about $14 \mathrm{wt} \% \mathrm{H}_{2}$ per g $\mathrm{LiBH}_{4}\left(3.5 \mathrm{wt} \% \mathrm{H}_{2}\right.$ per g sample) after dwelling for $25 \mathrm{~min}$ at $400{ }^{\circ} \mathrm{C}$. Ni is a typical catalyst for hydrogen dissociation and recombination. However its addition did not have a significant effect on the hydrogen desorption, suggesting that either the recombination of atomic hydrogen to molecular hydrogen is not the rate limiting step in the dehydrogenation of $\mathrm{LiBH}_{4}$ or that the $\mathrm{Ni}$ has reacted during synthesis.

To evaluate the reversible hydrogen uptake behaviour of the nanocomposites at mild conditions, the dehydrogenated samples were rehydrogenated in an autoclave at $320{ }^{\circ} \mathrm{C}, 40$ bar $\mathrm{H}_{2}$ for $120 \mathrm{~min}$. Fig. 2 shows the hydrogen release from the rehydrogenated samples upon heating to $400{ }^{\circ} \mathrm{C}$ and dwelling at this temperature for

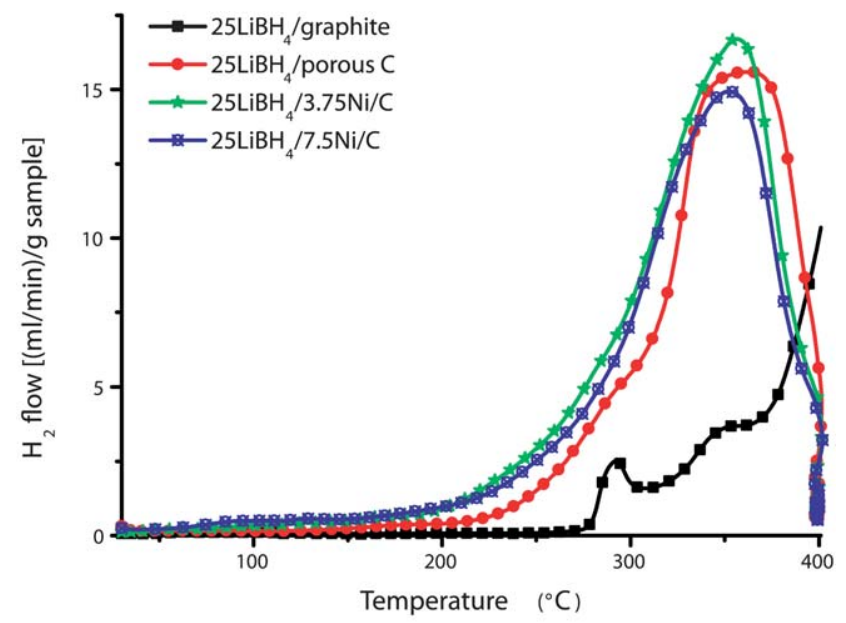

Fig. 1 Hydrogen release from $25 \mathrm{LiBH}_{4} /$ non porous graphite, $25 \mathrm{LiBH}_{4} / \mathrm{C}, 25 \mathrm{LiBH}_{4} / 3.75 \mathrm{Ni} / \mathrm{C}$ and $25 \mathrm{LiBH}_{4} / 7.5 \mathrm{Ni} / \mathrm{C}$. 


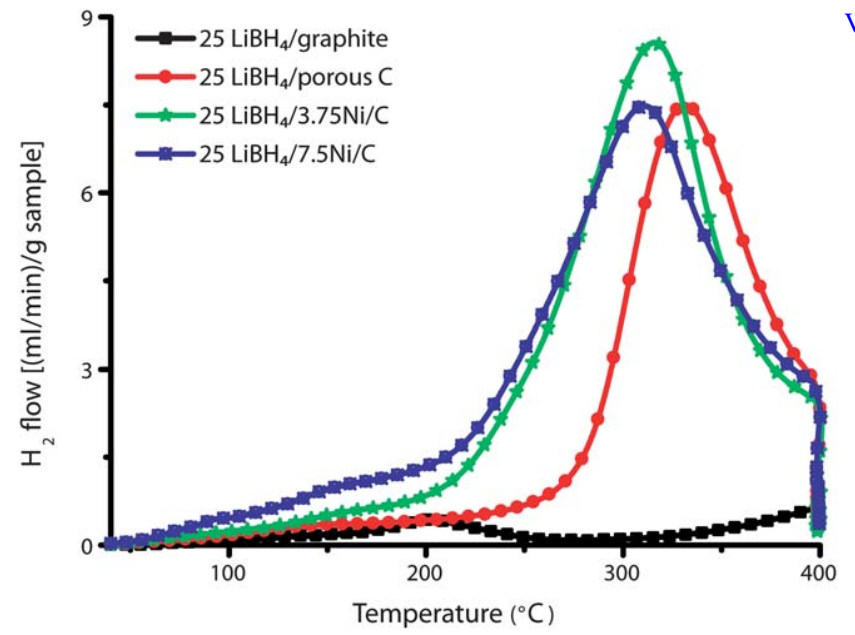

Fig. 2 Hydrogen release from samples after rehydrogenation for $120 \mathrm{~min}$ at $320^{\circ} \mathrm{C}$ and $40 \mathrm{bar}$ hydrogen: $25 \mathrm{LiBH}_{4} /$ non porous graphite, and nanocomposites of $25 \mathrm{LiBH}_{4} / \mathrm{C}, 25 \mathrm{LiBH}_{4} /$ $3.75 \mathrm{Ni} / \mathrm{C}$ and $25 \mathrm{LiBH}_{4} / 7.5 \mathrm{Ni} / \mathrm{C}$.

$25 \mathrm{~min}$. Only a negligible amount of hydrogen was released from the rehydrogenated $\mathrm{LiBH}_{4} /$ graphite sample. This suggests rehydrogenation was not successful which is in line with the fact that bulk $\mathrm{LiBH}_{4}$ requires about $600{ }^{\circ} \mathrm{C}$ and 350 bar $\mathrm{H}_{2}$ for rehydrogenation. ${ }^{3,4}$ In contrast, the rehydrogenated $\mathrm{LiBH}_{4} /$ porous $\mathrm{C}$ nanocomposite released about $6 \mathrm{wt}^{\%} \mathrm{H}_{2}$ per $\mathrm{g} \mathrm{LiBH}_{4}\left(1.5 \mathrm{wt} \% \mathrm{H}_{2}\right.$ per g sample) indicating that hydrogen was absorbed during rehydrogenation. Surprisingly, the two Ni-containing samples released about $9.2 \mathrm{wt} \% \mathrm{H}_{2}\left(2.3 \mathrm{wt} \% \mathrm{H}_{2}\right.$ per g sample $)$. Similar to the first hydrogen release cycle, increasing the Ni concentration did not lead to an increase in the hydrogen desorption rate nor in the amount of hydrogen released in the second cycle. However, in contrast to the first hydrogen desorption cycle, in the second cycle there is a clear difference in the hydrogen desorption pattern of the nanocomposites with and without $\mathrm{Ni}$. With $\mathrm{Ni}$ the onset temperature of the hydrogen release was significantly lower, and significantly more hydrogen was released between 250 and $300{ }^{\circ} \mathrm{C}$. These differences in the hydrogen release profiles for the rehydrogenated nanocomposites suggest that the microstructure of the $\mathrm{LiBH}_{4}$ formed after rehydrogenation might be influenced by the presence of $\mathrm{Ni}$, or that a $\mathrm{Ni}$-containing catalytically active component was only formed after the first dehydrogenation. Xia et al. recently showed that $\mathrm{LiBH}_{4}$ ball milled with $\mathrm{Ni}$ can reversibly absorb about $12 \mathrm{wt} \%$ $\mathrm{H}_{2}$ only when rehydrogenated for $30 \mathrm{~h}$ at $600{ }^{\circ} \mathrm{C}$ and 100 bar $\mathrm{H}_{2} \cdot{ }^{16}$ Hence, the results presented above clearly show the effectiveness of combining nanoconfinement and $\mathrm{Ni}$ addition to enhance the reversibility of the hydrogen desorption from $\mathrm{LiBH}_{4}$.

\section{Bulk characterization}

It is interesting to investigate the role of $\mathrm{Ni}$ in more detail. To this end, possible structural changes occurring in the nanocomposites during the different stages were analyzed using XRD and TEM. Fig. 3 shows the XRD patterns of the porous carbon, $5 \mathrm{wt} \% \mathrm{Ni} / \mathrm{C}$ nanocomposite, and the $\mathrm{LiBH}_{4} / \mathrm{Ni} / \mathrm{C}$ nanocomposites after synthesis, dehydrogenation and rehydrogenation. The XRD pattern of the carbon shows three diffraction lines at $31^{\circ}, 52^{\circ}$ and $64^{\circ} 2 \theta$ that are typical for turbostratic carbon materials. In addition to these diffraction lines, the $\mathrm{Ni}$ impregnated carbon shows two broad diffraction peaks around $53^{\circ}$ and $60^{\circ} 2 \theta$ that are due to crystalline $\mathrm{Ni}$ with an average crystallite size of $6 \mathrm{~nm}$. After melt infiltration with $\mathrm{LiBH}_{4}$, the $\mathrm{Ni}$ diffraction lines have disappeared. Upon dehydrogenation, no diffraction line other 


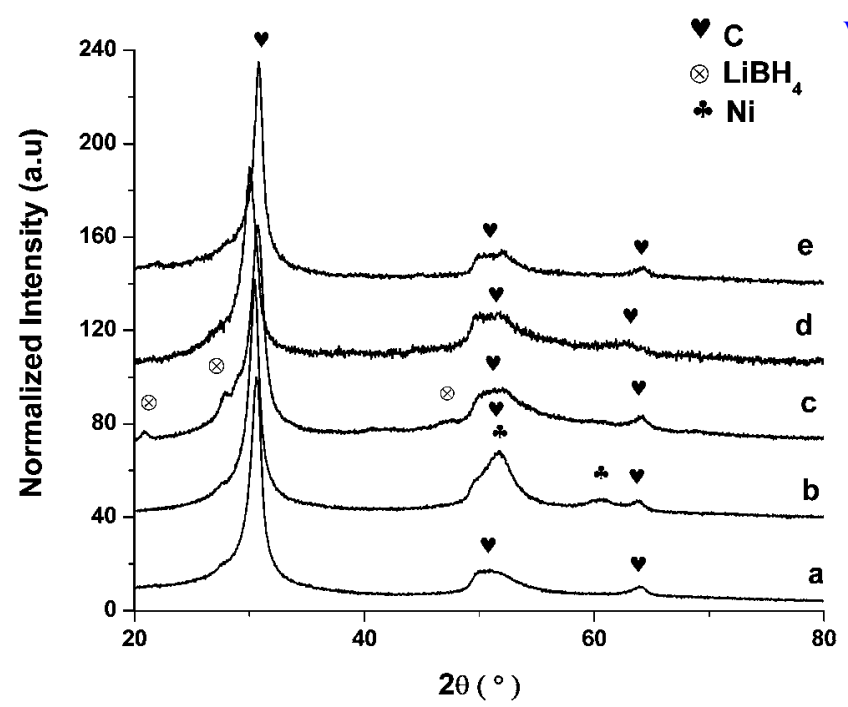

Fig. 3 XRD patterns of pure porous carbon (a); $5 \mathrm{wt} \% \mathrm{Ni} / \mathrm{C}$ (b); and the $25 \mathrm{LiBH}_{4} / 3.75 \mathrm{Ni} / \mathrm{C}$ nanocomposite after synthesis (c), dehydrogenation (d) and rehydrogenation (e).

than that of the carbon material was seen and this is same for the rehydrogenated samples. This shows that the crystalline Ni nanoparticles are no longer present after melt infiltration. This could be due to reaction with $\mathrm{LiBH}_{4}$ during melt. For the $\mathrm{LiBH}_{4}$, only very weak diffraction lines were seen after melt infiltration (spectrum c) indicating that the material is not crystalline, and most likely confined in the nanopores. ${ }^{7}$ Nitrogen physisorption (Fig. S1 in supporting information $\dagger$ ) shows that the carbon pore volume drastically reduced after melt infiltration due to incorporation of $\mathrm{LiBH}_{4}$ into the pores.

Interestingly, a comparison of patterns (d) and (e) shows a reversible shift in the $\mathrm{C}$ (002) diffraction line from $31^{\circ}$ to $29.9^{\circ} 2 \theta$ and back upon dehydrogenation and rehydrogenation. Such a shift corresponds to a change in the average graphene interlayer spacing by $0.08 \AA$. As it is reversible, and occurs upon dehydrogenation (forming metallic $\mathrm{Li}$ ) it is logical to ascribe it to $\mathrm{Li}$ intercalation in the graphitic carbon. ${ }^{34-36}$ Similar behaviour is observed for the samples with and without $\mathrm{Ni}$. Previously it has been reported that $\mathrm{Na}$ could be reversibly intercalated into this graphitic carbon upon dehydrogenation of $\mathrm{NaH}^{37}$ As far as we are aware, this is the first report of reversible $\mathrm{Li}$ intercalation in carbon during the dehydrogenation of $\mathrm{LiBH}_{4}$. For full intercalation of $\mathrm{Li}$ to form $\mathrm{LiC}_{6}$, a change in lattice spacing of $0.35 \AA$ would be expected. ${ }^{36,38}$ Hence, in this case intercalation was limited (on the average forming $\mathrm{Li}_{0.23} \mathrm{C}_{6}$ ). It might be of great importance if this effect could be enhanced, as it stabilizes the metallic phase and hence decreases the enthalpy difference between hydrided and dehydrided phase. However, a detailed investigation of this effect is outside the scope of the present paper.

To investigate whether the Ni nanoparticles had withstood melt infiltration with $\mathrm{LiBH}_{4}$, we further investigated the microstructure of the nanocomposites by acquiring TEM micrographs of the samples at different stages of treatment. A representative TEM micrograph of the $5 \mathrm{wt} \% \mathrm{Ni} / \mathrm{C}$ nanocomposite (Fig. 4A) shows well dispersed and homogenously distributed $\mathrm{Ni}$ nanoparticles with a number-averaged particle size of 5-6 nm which is in good agreement with the volume-averaged crystallite size of $6 \mathrm{~nm}$ obtained from the XRD pattern using the Scherrer formula. Analysis of the electron diffraction pattern (see Fig. S2 $\dagger$ ) shows that the signal is due to diffraction from the graphitic carbon ( $d$-values of 1.68 and $1.54 \AA$ ) and $\mathrm{Ni}(2.03$ and $1.25 \AA$ ). Fig. 4B shows that after melt infiltrating the Ni/C nanocomposite with 

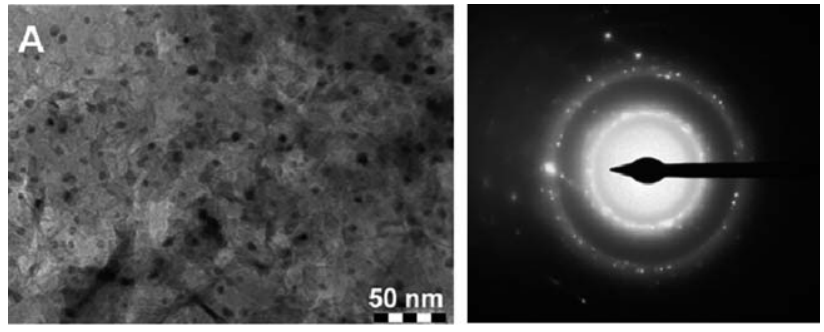

View Article Online
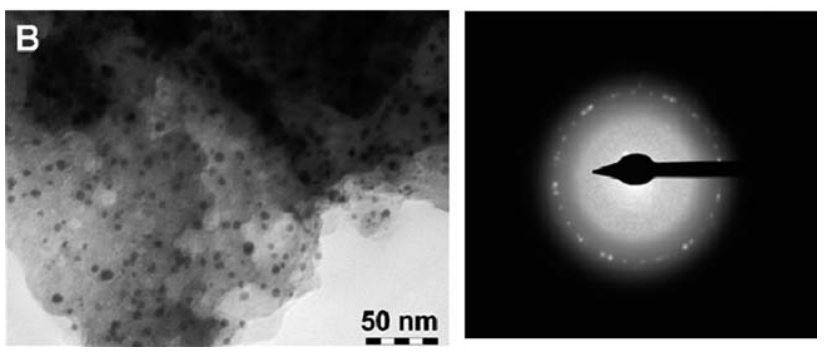

Fig. 4 TEM images and electron diffraction of (A) $5 \mathrm{wt} \% \mathrm{Ni} / \mathrm{C}$; (B) $5 \mathrm{wt} \% \mathrm{Ni} / \mathrm{C}$ after melt infiltrating with $25 \mathrm{wt} \% \mathrm{LiBH}_{4}\left(25 \mathrm{LiBH}_{4} / 3.75 \mathrm{Ni} / \mathrm{C}\right)$.

$25 \mathrm{wt}^{\mathrm{T}} \% \mathrm{LiBH}_{4}$ (to form $\mathrm{LiBH}_{4} / \mathrm{Ni} / \mathrm{C}$ nanocomposites), nanoparticles with average size of $7 \mathrm{~nm}$ were still present but the electron diffraction detects only graphitic carbon ( $d$-values of 1.67 and $1.54 \AA$ ) as a crystalline phase, showing that these nanoparticles are amorphous. Energy-dispersive X-ray (EDX) measurement on the same sample reveals that the nanoparticles contain $\mathrm{Ni}$ (Fig. $\mathrm{S} 3 \dagger$ ). $\mathrm{LiBH}_{4}$ cannot be reliably imaged with TEM due to weak scattering of electrons by the light elements $\mathrm{Li}$ and $\mathrm{B}$. The electron micrographs of the dehydrogenated and rehydrogenated samples (not shown here) looked similar to that of the melt infiltrated sample, with amorphous Ni-containing nanoparticles. Apparently the Ni has reacted during melt infiltration with the $\mathrm{LiBH}_{4}$, forming amorphous/or non crystalline nanoparticles that are rich in $\mathrm{Ni}$, and roughly maintain their morphology upon cycling.

\section{Characterization of the $\mathrm{Ni}$ chemical environment}

As these particles are non-crystalline, Extended X-ray Absorption Fine Structure spectroscopy (EXAFS) at the Ni K-edge was used to characterize the local environment of Ni. Fig. 5 shows the phase-uncorrected Fourier transform (FT) of the EXAFS spectra of $5 \mathrm{wt} \% \mathrm{Ni} / \mathrm{C}$, and the $\mathrm{LiBH}_{4} / \mathrm{Ni} / \mathrm{C}$ nanocomposite after synthesis, dehydrogenation and rehydrogenation. For $5 \mathrm{wt} \% \mathrm{Ni} / \mathrm{C}$ a main peak is visible around $2.2 \AA$ which is representative for $\mathrm{Ni}-\mathrm{Ni}$ scattering in metallic $\mathrm{Ni}$ (Fig. 5(a)). The signals at larger distances are representative for Ni present in higher coordination shells as expected for crystalline metallic Ni. The main peak at $2.2 \AA$ shifted to $2.1 \AA$ and decreased in intensity after melt infiltration of $\mathrm{LiBH}_{4}$. This indicates a significant change of the coordination around $\mathrm{Ni}$ after melt infiltration. In addition, after melt infiltration, no higher shells were observed which suggests that the sample lacked long range order, or consisted of nanosized clusters, in line with XRD and TEM results.

The fitting results and theoretical crystal structure of $\mathrm{Ni}-\mathrm{B}$ compounds are listed in Table 1. The quality of the fit can be appreciated from Fig. S4 (supporting information $\dagger$ ). For the $\mathrm{Ni} / \mathrm{C}$, Ni was surrounded by $8 \mathrm{Ni}$ neighbors at $2.47 \AA$ indicative of $\mathrm{Ni}$ particles of a few nanometres. After melt infiltration with $\mathrm{LiBH}_{4}, \mathrm{Ni}$ was surrounded by $4.6 \mathrm{~B}$ neighbors at $2.07 \AA$ and $4.2 \mathrm{Ni}$ neighbors at $2.47 \AA$. By comparing these values to those of the reference compounds $\left(\mathrm{Ni}, \mathrm{NiB}, \mathrm{Ni}_{2} \mathrm{~B}\right.$ and 

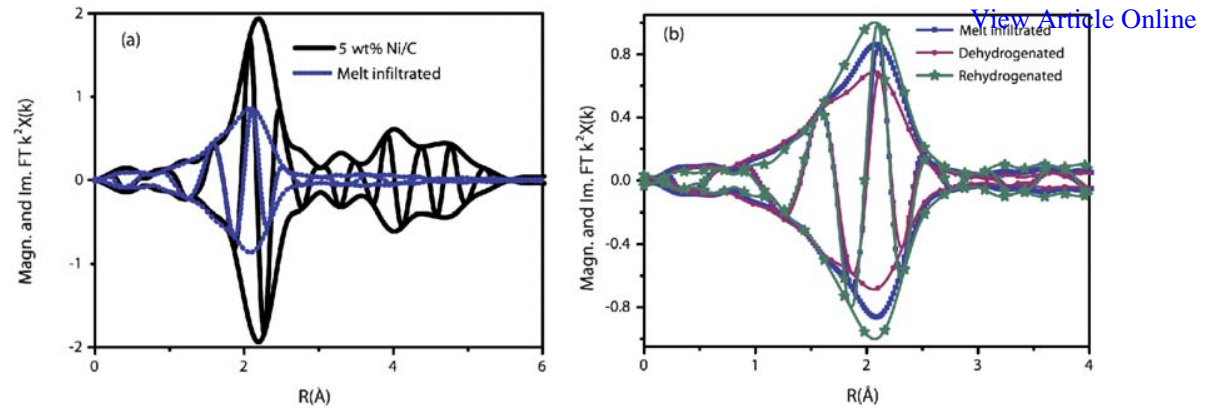

Fig. 5 Magnitude and imaginary part of the phase-uncorrected Fourier transformed (FT) $k^{2} \chi(k)$ for (a) $5 \mathrm{wt} \% \mathrm{Ni} / \mathrm{C}$ and the $25 \mathrm{LiBH}_{4} / 3.75 \mathrm{Ni} / \mathrm{C}$ nanocomposite after melt infiltration, (b) melt infiltrated, dehydrogenated and rehydrogenated states of the $25 \mathrm{LiBH}_{4} / 3.75 \mathrm{Ni} / \mathrm{C}$ nanocomposite.

Table 1 Local structure parameters including neighbour type, inter atomic distance $(R)$ and Debye-Waller factor $\left(\sigma^{2}\right)$ for $\mathrm{Ni}$ in $5 \mathrm{wt} \% \mathrm{Ni} / \mathrm{C}$ and $\mathrm{LiBH}_{4} / \mathrm{Ni} / \mathrm{C}$ nanocomposites at different stages. The fit is optimized with $\Delta k=3-13 \AA^{-1}$ and $\Delta R=1.2-3.0$ with a $k$-weighting parameter of 2. The parameters of the $\mathrm{NiB}, \mathrm{Ni}_{2} \mathrm{~B}, \mathrm{Ni}_{3} \mathrm{~B}$ and $\mathrm{Ni}$ references are included for comparison

\begin{tabular}{llllllll}
\hline \multirow{2}{*}{ Sample } & & & & & & & \multicolumn{2}{c}{$k^{2}$-variance } \\
\hline \multirow{2}{*}{$5 \mathrm{wt} \% \mathrm{Ni} / \mathrm{C}$} & $\mathrm{Shell}$ & Neighbors & $\Delta \sigma^{2}\left(10^{-3} \AA^{2}\right)$ & $R(\AA)$ & $\Delta E_{0}(\mathrm{eV})$ & Abs. & Img. \\
Melt infiltrated & $\mathrm{Ni}-\mathrm{Ni}$ & 8.1 & 1.46 & 2.474 & 0.03 & 0.09 & 0.11 \\
& $\mathrm{Ni}-\mathrm{B}$ & 4.6 & 1.62 & 2.07 & 10.7 & 0.06 & 0.28 \\
Dehydrogenated & $\mathrm{Ni}-\mathrm{Ni}$ & 4.2 & 5.83 & 2.47 & 7.9 & & \\
& $\mathrm{Ni}-\mathrm{B}$ & 5.3 & 2.56 & 2.07 & 11.4 & 0.03 & 0.25 \\
\multirow{2}{*}{ Rehydrogenated } & $\mathrm{Ni}-\mathrm{Ni}$ & 3.4 & 6.03 & 2.48 & 8.4 & & \\
& $\mathrm{Ni}-\mathrm{B}$ & 3.8 & 2.19 & 2.07 & 11.9 & 0.08 & 0.28 \\
$\mathrm{NiB}^{36}$ & $\mathrm{Ni}-\mathrm{Ni}$ & 6.9 & 9.08 & 2.46 & 9.4 & & \\
& $\mathrm{Ni}-\mathrm{B}$ & 7 & - & 2.16 & - & - & - \\
& $\mathrm{Ni}-\mathrm{Ni}$ & 6 & - & 2.60 & - & - & - \\
$\mathrm{Ni}_{2} \mathrm{~B}^{35}$ & $\mathrm{Ni}-\mathrm{Ni}$ & 4 & - & 2.95 & - & - & - \\
& $\mathrm{Ni}-\mathrm{B}$ & 4 & - & 2.14 & - & - & - \\
& $\mathrm{Ni}-\mathrm{Ni}$ & 3 & - & 2.40 & - & - & - \\
$\mathrm{Ni}_{3} \mathrm{~B}^{34}$ & $\mathrm{Ni}-\mathrm{Ni}$ & 8 & - & 2.67 & - & - & - \\
& $\mathrm{Ni}-\mathrm{B}$ & 3 & - & 2.13 & - & - & - \\
& $\mathrm{Ni}-\mathrm{Ni}$ & 8 & - & 2.50 & - & - & - \\
$\mathrm{Ni}^{34}$ & $\mathrm{Ni}-\mathrm{Ni}$ & 3 & - & 2.74 & - & - & - \\
& $\mathrm{Ni}-\mathrm{Ni}$ & 12 & - & 2.49 & - & - & - \\
\hline
\end{tabular}

$\mathrm{Ni}_{3} \mathrm{~B}$ ), it can be concluded that the structure of the sample is most similar to that of $\mathrm{Ni}_{2} \mathrm{~B}$. A smaller amount of other phases must be present as well, although the data do not allow a more detailed analysis of the composition. The Ni-Ni distances in $\mathrm{Ni}_{2} \mathrm{~B}$ and $\mathrm{Ni}_{3} \mathrm{~B}$ are close to that in metallic $\mathrm{Ni}$, making it difficult to discuss the exact nature of the $\mathrm{Ni}-\mathrm{Ni}$ scattering. Large $E_{0}$ shifts were observed for $\mathrm{Ni}-\mathrm{Ni}$ and $\mathrm{Ni}-\mathrm{B}$ scattering in the samples indicating that the coordination and/or nature of the scattering in the references used to fit the data was different from that in the samples. For $\mathrm{Ni}-\mathrm{Ni}$ this is logical as a $\mathrm{Ni}$-foil was used to extract the reference data while $\mathrm{Ni}-\mathrm{Ni}$ in $\mathrm{Ni}-\mathrm{B}$ compounds is different in nature. For $\mathrm{Ni}-\mathrm{B}$ this is more difficult to explain since $\mathrm{Ni}_{2} \mathrm{~B}$ was used as a reference. However the fitting of the data does not show 
a perfect fit with $\mathrm{Ni}_{2} \mathrm{~B}$ as discussed above which might indicate the sample \&@asistsiofe Online a number of phases which makes the choice of a proper reference challenging.

A comparison of the FT EXAFS data after melt infiltration, dehydrogenation and rehydrogenation is shown in Fig. 5(b). After dehydrogenation the signal at $2.1 \AA$ decreased in intensity and increased again after rehydrogenation. The fitting results of these samples are shown in Table 1. After dehydrogenation the Ni-B coordination number increased, from 4.6 to 5.3 , while the $\mathrm{Ni}-\mathrm{Ni}$ coordination decreased from 4.2 to 3.4. This indicates that more $\mathrm{B}$ reacted with Ni during dehydrogenation which can be expected since dehydrogenation resulted in the formation of significant amounts of $\mathrm{B}$. After rehydrogenation the $\mathrm{Ni}-\mathrm{B}$ coordination decreased again from 5.3 to 3.8 while the $\mathrm{Ni}-\mathrm{Ni}$ coordination increased again from 3.4 to 6.9. This shows the reversible behaviour of the sample. Since the $\mathrm{Ni}-\mathrm{Ni}$ coordination is higher than in the melt infiltrated sample and the $\mathrm{Ni}-\mathrm{B}$ is lower, it is tempting to speculate that more $\mathrm{Ni}_{3} \mathrm{~B}$ is formed after rehydrogenation. This is in line with the stability of different $\mathrm{Ni}-\mathrm{B}$ compounds at room temperature: $\mathrm{Ni}_{3} \mathrm{~B}>\mathrm{NiB}>\mathrm{Ni}_{2} \mathrm{~B}^{39}$

The EXAFS results show that nickel borides $\left(\mathrm{Ni}_{x} \mathrm{~B}\right)$ are formed after synthesis, dehydrogenation and rehydrogenation of the $\mathrm{LiBH}_{4} / \mathrm{Ni} / \mathrm{C}$, with the value of $x$ depending on the state. Therefore the improved reversibility in this system is related to the formation of the nickel boride nanoparticles. Although nickel boride has been used as a catalyst in hydrogenation processes, ${ }^{40-45}$ an interesting question is how $\mathrm{Ni}_{x} \mathrm{~B}$ improves the reversible hydrogen uptake in the $\mathrm{LiBH}_{4} / \mathrm{Ni} / \mathrm{C}$ nanocomposites. A possible explanation is that the nickel boride acts as hydrogenation catalyst, lowering the barrier for the formation of borohydride anions $\left(\mathrm{BH}_{4}^{-}\right)$as recently reported in the literature. ${ }^{46}$ In this case it is expected that the rate at which hydrogen is absorbed in the $\mathrm{Ni}$ containing nanocomposites will be higher, reaching the maximum capacity faster than the sample without Ni. However an investigation of the hydrogen uptake behaviour in the nanocomposites show that the nickel boride does not only enhance the overall uptake rates but its presence also seems to increase the fraction of the material that can be rehydrogenated under mild conditions. ${ }^{29}$ Other possible roles of nickel boride in the nanocomposite could be to act as a nucleation site for the reversible formation of $\mathrm{LiBH}_{4}$ from the dehydrogenated products, and/or that its presence influences the microstructure of the nanocomposites during desorption and rehydrogenation.

\section{NMR investigation of the microstructure}

EXAFS is not suitable to investigate the lighter elements such as $\mathrm{Li}$ and $\mathrm{B}$. Therefore, we further investigated the B-containing compounds present in the nanocomposites at different stages using solid-state ${ }^{11} \mathrm{~B}$ NMR. ${ }^{47}$ Please note that Nicontaining species will not be evident in these spectra. Fig. 6 shows the ${ }^{11} \mathrm{~B}$ NMR spectra of the nanocomposites after synthesis and rehydrogenation, including the spectrum for $\mathrm{LiBH}_{4}$ physically mixed with porous carbon. The ${ }^{11} \mathrm{~B}$ spectrum of a physical mixture of $\mathrm{LiBH}_{4}$ and porous carbon shows a well defined sharp peak at $-42 \mathrm{ppm}$. The $\mathrm{LiBH}_{4}$ lineshape is clearly broadened in both nanocomposites after synthesis due to close contact of the $\mathrm{LiBH}_{4}$ with the carbon. The broadening can be explained by a variation in local magnetic field due to the anisotropic susceptibility of the carbon. In addition, we expect a broadening due to the higher disorder, which results in a distribution in chemical shift and quadrupolar interaction parameters, as reported for $\mathrm{NaAlH}_{4}$ confined in nanoporous carbon. ${ }^{48,49}$

After the samples have been dehydrogenated and rehydrogenated, in addition to the peak due to $\mathrm{LiBH}_{4}$, both samples show the presence of an additional peak around $-15 \mathrm{ppm}$ chemical shift which is assigned to the intermediate compound $\mathrm{Li}_{2} \mathrm{~B}_{12} \mathrm{H}_{12} \cdot{ }^{50,51}$ However two major differences exist between the rehydrogenated samples.

Firstly, the intensity of $\mathrm{Li}_{2} \mathrm{~B}_{12} \mathrm{H}_{12}$ is smaller in the sample with $\mathrm{Ni}$, which is in line with the fact that more of the desorbed components are rehydrogenated back to 


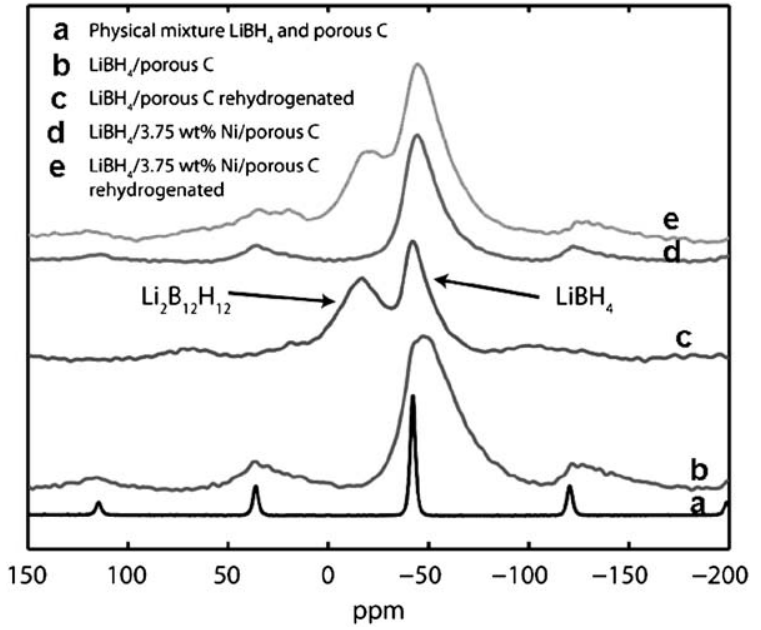

Fig. 6 Solid-state ${ }^{11} \mathrm{~B}$ NMR spectra of a physical mixture of $25 \mathrm{wt} \% \mathrm{LiBH}_{4}$ and porous carbon and the melt infiltrated nanocomposites with and without $\mathrm{Ni}$ after synthesis and rehydrogenation for $4 \mathrm{~h}$ at $320^{\circ} \mathrm{C}, 40$ bar $\mathrm{H}_{2}$.

$\mathrm{LiBH}_{4}$ in this sample. Secondly, the rehydrogenated Ni-containing samples have a $\mathrm{LiBH}_{4}$ peak which is very similar to that in the as-synthesized samples both in the intensity and line width, while the sample without $\mathrm{Ni}$ shows a narrower $\mathrm{LiBH}_{4}$ peak with lower intensity compared to both the as-synthesized sample and the rehydrogenated $\mathrm{Ni}$-containing nanocomposite. These results suggest a change in microstructure or distribution of $\mathrm{LiBH}_{4}$ in the carbon material for the sample without $\mathrm{Ni}$ upon cycling, with a tendency toward phase separation and increased cluster size. Since the broadening of the linewidth is related to the contact between the $\mathrm{LiBH}_{4}$ and porous $\mathrm{C},{ }^{48,49}$ the $\mathrm{LiBH}_{4}$ in the as-synthesized sample possibly has a closer contact with the carbon than in the rehydrogenated sample. For the Ni containing sample the NMR data suggest that the $\mathrm{LiBH}_{4}$ distribution is retained upon cycling as similar lineshapes are observed before and after rehydrogenation. This could also explain the observed lower desorption temperatures in the rehydrogenated nanocomposite with $\mathrm{Ni}$ compared to the sample without Ni (Fig. 2).

The observed differences in the ${ }^{11} \mathrm{~B}$ NMR spectra of the rehydrogenated nanocomposites shows that the presence of the nickel boride nanoparticles influenced the microstructural evolution of the boron phases in the compound upon dehydrogenation and rehydrogenation.

\section{Conclusion}

We studied the structure and phase evolution in $\mathrm{LiBH}_{4} / \mathrm{Ni} / \mathrm{C}$ nanocomposites, and the role of $\mathrm{Ni}$, during hydrogen cycling. XRD and TEM measurements show that after sample preparation Ni-containing nanoparticles are present. However, they are neither metallic Ni nor crystalline. EXAFS revealed that the local structure of this nickel boride phase is most similar to that of $\mathrm{Ni}_{2} \mathrm{~B}$, although a smaller amount of other phases was present as well. Interestingly, upon hydrogen cycling of the $\mathrm{LiBH}_{4}$, the chemical environment in this nanophase changes reversibly, with a higher $\mathrm{Ni}-\mathrm{B}$ coordination in the dehydrogenated state. $\mathrm{Ni}_{x} \mathrm{~B}$ is known to be able to act as a hydrogenation catalyst. However, ${ }^{11} \mathrm{~B}$ NMR results showed that the presence of $\mathrm{Ni}$ also influenced the microstructural evolution of the $\mathrm{LiBH}_{4}$. In the absence of $\mathrm{Ni}$ a change in the nanoconfined $\mathrm{LiBH}_{4}$ microstructure upon cycling was observed, while this was not the case in the presence of Ni. From these structural studies it 
has become clear that $\mathrm{Ni}$ does not simply act as a (de)hydrogenation catalystein Ahese Online systems. It reacts to form $\mathrm{Ni}_{x} \mathrm{~B}$ nanoparticles which reversibly interact with the boron being formed upon dehydrogenation of the $\mathrm{LiBH}_{4}$. The presence of these particles enhances the stability of the microstructure of the nanoconfined $\mathrm{LiBH}_{4}$ upon cycling.

\section{Acknowledgements}

We acknowledge M. (Rien) van Zwienen, A. van der Eerden, A. Mens, and V. Koot, for their technical support, and NWO-Vidi 016.072.316 for financial support. The Nederlandse Organisatie voor Wetenschappelijk Onderzoek (NWO) is acknowledged for support of the "Solid-state NMR facility for advanced materials science". Support of HASYLAB and HASYLAB staff, Project Number II-20090124 EC, is gratefully acknowledged for the EXAFS, Johannes H. Meeldijk for TEM measurements and Timcal Switzerland for providing the carbon.

\section{References}

1 J. Yang, A. Sudik, C. Wolverton and D. J. Siegel, Chem. Soc. Rev., 2010, 39, 656-675.

2 L. Schlapbach and A. Züttel, Nature, 2001, 414, 353-358.

3 P. Mauron, F. Buchter, O. Friedrichs, A. Remhof, M. Bielmann, C. N. Zwicky and A. Zuttel, J. Phys. Chem. B, 2008, 112, 906-910.

4 S. Orimo, Y. Nakamori, G. Kitahara, K. Miwa, N. Ohba, S. Towata and A. Zuttel, $J$. Alloys Compd., 2005, 404, 427-430.

5 A. F. Gross, J. J. Vajo, S. L. Van Atta and G. L. Olson, J. Phys. Chem. C, 2008, 112, 56515657.

6 Y. Zhang, W.-S. Zhang, A.-Q. Wang, S. Li-Xian, M.-Q. Fan, H.-L. Chu, J.-C. Sun and T. Zhang, Int. J. Hydrogen Energy, 2007, 32, 3976-3980.

7 Z. Z. Fang, P. Wang, T. E. Rufford, X. D. Kang, G. Q. Lu and H. M. Cheng, Acta Mater., 2008, 56, 6257-6263.

8 S. Cahen, J. B. Eymery, R. Janot and J. M. Tarascon, J. Power Sources, 2009, 189, 902-908.

9 P. Adelhelm and P. E. de Jongh, J. Mater. Chem., 2011, 21, 2417-2427.

10 P. E. de Jongh and P. Adelhelm, ChemSusChem, 2010, 3, 1332-1348.

11 A. Züttel, S. Rentsch, P. Fischer, P. Wenger, P. Sudan, P. Mauron and C. Emmenegger, J. Alloys Compd., 2003, 356-357, 515-520.

12 M. Au, A. R. Jurgensen, W. A. Spencer, D. L. Anton, F. E. Pinkerton, S. J. Hwang, C. Kim and R. C. Bowman, J. Phys. Chem. C, 2008, 112, 18661-18671.

13 Z. Z. Fang, X. D. Kang, P. Wang and H. M. Cheng, J. Phys. Chem. C, 2008, 112, 1702317029 .

14 J. J. Vajo, S. L. Skeith and F. Mertens, J. Phys. Chem. B, 2005, 109, 3719-3722.

15 M. S. Wellons, P. A. Berseth and R. Zidan, Nanotechnology, 2009, 20.

16 G. L. Xia, Y. H. Guo, Z. Wu and X. B. Yu, J. Alloys Compd., 2009, 479, 545-548.

17 J. Xu, X. B. Yu, Z. Q. Zou, Z. L. Li, Z. Wu, D. L. Akins and H. Yang, Chem. Commun., $2008,5740-5742$.

18 A. Gutowska, L. Y. Li, Y. S. Shin, C. M. M. Wang, X. H. S. Li, J. C. Linehan, R. S. Smith, B. D. Kay, B. Schmid, W. Shaw, M. Gutowski and T. Autrey, Angew. Chem., Int. Ed., 2005, 44, 3578-3582.

19 C. P. Balde, B. P. C. Hereijgers, J. H. Bitter and K. P. de Jong, Angew. Chem., Int. Ed., 2006, 45, 3501-3503.

20 J. Gao, P. Adelhelm, M. H. W. Verkuijlen, C. Rongeat, M. Herrich, P. J. M. van Bentum, O. Gutfleisch, A. P. M. Kentgens, K. P. de Jong and P. E. de Jongh, J. Phys. Chem. C, 2010, 114, 4675-4682.

21 W. Lohstroh, A. Roth, H. Hahn and M. Fichtner, ChemPhysChem, 2010, 11, 789-792.

22 B. Bogdanovič and M. Schwickardi, J. Alloys Compd., 1997, 253, 1-9.

23 Y. Zhang, W.-S. Zhang, M.-Q. Fan, S.-S. Liu, H.-L. Chu, Y.-H. Zhang, X.-Y. Gao and L.X. Sun, J. Phys. Chem. C, 2008, 112, 4005-4010.

24 L. Mosegaard, B. Moller, J. E. Jorgensen, Y. Filinchuk, Y. Cerenius, J. C. Hanson, E. Dimasi, F. Besenbacher and T. R. Jensen, J. Phys. Chem. C, 2008, 112, 1299-1303.

25 X. B. Yu, D. A. Grant and G. S. Walker, J. Phys. Chem. C, 2008, 112, 11059-11062.

26 S. M. Opalka, X. Tang, B. L. Laube and T. H. Vanderspurt, Nanotechnology, 2009, 20.

27 M. Au and A. Jurgensen, J. Phys. Chem. B, 2006, 110, 7062-7067. 
28 X. D. Kang, P. Wang, L. P. Ma and H. M. Cheng, Appl. Phys. A: Mater. SkdieRrekrtisle Online 2007, 89, 963-966.

29 P. Ngene, M. van Zwienen and P. E. de Jongh, Chem. Commun., 2010, 46, 8201-8203.

30 R. Bogerd, P. Adelhelm, J. H. Meeldijk, K. P. de Jong and P. E. de Jongh, Nanotechnology, 2009, 20, 204019.

31 M. Vaarkamp, J. C. Linders and D. C. Koningsberger, Phys. B, 1995, 208-209, 159-160.

32 J. W. Cook Jr and D. E. Sayers, J. Appl. Phys., 1981, 52, 5024-5031.

33 D. C. Koningsberger, B. L. Mojet, G. E. Van Dorssen and D. E. Ramaker, Top. Catal., $2000,10,143-155$.

34 X. Y. Song, K. Kinoshita and T. D. Tran, J. Electrochem. Soc., 1996, 143, L120-L123.

35 G. Maurin, C. Bousquet, F. Henn, P. Bernier, R. Almairac and B. Simon, Chem. Phys. Lett., 1999, 312, 14-18.

36 D. Billaud, E. McRae and A. Hérold, Mater. Res. Bull., 1979, 14, 857-864.

37 P. Adelhelm, K. P. de Jong and P. E. de Jongh, Chem. Commun., 2009, 6261-6263.

38 N. A. Kaskhedikar and J. Maier, Adv. Mater., 2009, 21, 2664-2680.

39 O. Teppo and P. Taskinen, Mater. Sci. Technol., 1993, 9, 205-212.

40 H. C. Brown and C. A. Brown, J. Am. Chem. Soc., 1963, 85, 1005-1006.

41 R. Paul, P. Buisson and N. Joseph, Ind. Eng. Chem., 1952, 44, 1006-1010.

42 C. M. Kaufman and B. Sen, J. Chem. Soc., Dalton Trans., 1985, 307-313.

43 C. A. Brown and V. K. Ahuja, J. Org. Chem., 1973, 38, 2226-2230.

44 J. C. Walter, A. Zurawski, D. Montgomery, M. Thornburg and S. Revankar, J. Power Sources, 2008, 179, 335-339.

45 D. Hua, Y. Hanxi, A. Xinping and C. Chuansin, Int. J. Hydrogen Energy, 2003, 28, 10951100 .

46 J. Graetz, S. Chaudhuri, T. T. Salguero, J. J. Vajo, M. S. Meyer and F. E. Pinkerton, Nanotechnology, 2009, 20.

47 Note that the Ni-containing species will not be evident from the NMR due to a paramagnetic effect of the Ni. This effect results in a very fast relaxation of the ${ }^{11} \mathrm{~B}$ magnetization and/or a distortion of the local magnetic field homogeneity and the intensity will be smeared out in the baseline. Therefore an accurate quantification of the phases is not possible at present due to unknown effects of the carbon susceptibility on the local RF field strengths and penetration depths and possible paramagnetic effects of the Ni.

48 P. Adelhelm, J. B. Gao, M. H. W. Verkuijlen, C. Rongeat, M. Herrich, P. J. M. van Bentum, O. Gutfleisch, A. P. M. Kentgens, K. P. de Jong and P. E. de Jongh, Chem. Mater., 2010, 22, 2233-2238.

49 M. H. W. Verkuijlen, J. B. Gao, P. Adelhelm, P. J. N. van Bentum, P. E. de Jongh and A. P. M. Kentgens, J. Phys. Chem. C, 2010, 114, 4683-4692.

50 O. Friedrichs, A. Remhof, S. J. Hwang and A. Züttel, Chem. Mater., 2010, 22, 3265-3268.

51 S. J. Hwang, R. C. Bowman, J. W. Reiter, J. Rijssenbeek, G. L. Soloveichik, J. C. Zhao, H. Kabbour and C. C. Ahn, J. Phys. Chem. C, 2008, 112, 3164-3169. 